\title{
Investigation of Tramway Line No. 1, in Budapest, Based on Dynamic Measurements
}

\author{
Vivien Jóvér ${ }^{1}$, László Gáspár², Szabolcs Fischer ${ }^{1}$ \\ ${ }^{1}$ Széchenyi István University \\ Egyetem tér 1, H-9026 Győr, Hungary \\ \{jover.vivien,fischersz\}@ sze.hu \\ ${ }^{2}$ KTI Institute for Transport Sciences Non-profit Ltd. \\ Than Károly u. 3-5, H-1119 Budapest, Hungary \\ gaspar.laszlo@kti.hu
}

\begin{abstract}
Determining the deterioration of superstructure systems is technical and has national economic importance. In addition to geometric deterioration, it is also very difficult to monitor the changes in the dynamic characteristics of the vehicles. The data from geometric and dynamic measurements should be properly analyzed to determine the deterioration, lifetimellife-cycle costs of superstructure systems and the casual relationships should be researched between the characteristics. In this paper, the geometric and dynamic measurement results of the two examined sections are compared. This analysis is the first step in exploring and understanding the relationship between each feature. The authors recommended methodologies for using the synchronized (static and dynamic) measurements and their evaluation possibilities related to tramway tracks. The method is a well-known solution for public railways; however, the tramways greatly differ. In Hungary, there is a great opportunity to introduce the static-dynamic parallel method, which can be applied for the determination of the life-cycle costs (LCC) of the tramway tracks that are assembled with different (super)structures.
\end{abstract}

Keywords: tramway track; superstructure systems; geometrical analysis; dynamic analysis, deterioration

\section{Introduction}

The deterioration of tramway tracks can be observed in several ways: the deterioration of tracks' structural elements (i.e., rails, rail fasteners sleepers, etc.) can be detected by inspection of the line; however, the changes in track geometric parameters like track gauge, alignment, longitudinal level, etc. can only be measured with instruments [1]. In addition to monitoring changes in the geometric characteristics, it is also essential to measure the dynamic characteristics of 
vehicles, record and assess the measurement results [2] [3]. Considering the dynamic effect in engineering design and maintenance is quite important [4-7]. Suppose the geometric and dynamic measurements are appropriately evaluated, and the costs are known for the whole lifetime; each superstructure system's life cycle, geometric deterioration, and life cycle cost can be determined.

In Hungary, seven types of superstructure systems are currently differentiated, but they are constructed differently in each case.

The authors selected 22 standard (reference) sections in the research, at least three for each known superstructure system, but these are different ages. The goal is to determine the deterioration of these sections considering the passage of time, their lifetime, and life cycle cost by regular inspection of the line, track geometric and dynamic examination [8].

\section{Survey of Tramway Track Condition in Hungary}

Three methods are applied in Hungary to examine the superstructure systems of tramway tracks:

- Inspection of the tramway line

- Geometric measurements

- Dynamic measurements

In Budapest (capital of Hungary), the inspections of the lines of running tracks are executed by the persons appointed for this task. It is specified in the Guidelines of infrastructure planning of tramway tracks by BKV PLC. [9].

For many years, the measurements of tracks' geometrical characteristics have been carried out by the TrackScan 4.01 instrument developed by Metalelektro Méréstechnika Ltd. The instrument is a complex track measuring device, which is suitable for continuous measurements. This equipment is able to measure and register the following characteristics at the same time [10]:

- Track gauge $[\mathrm{mm}]$

- $\quad$ Flange gauge $[\mathrm{mm}]$

- Superelevation $[\mathrm{mm}]$

- Alignment [mm]

- Longitudinal level [mm]

- $\quad$ Length of the railway section [in meters to the nearest $\mathrm{mm}$ ]

- $\quad$ Twist $[\mathrm{mm}]$ 
The disadvantage of this instrument (Fig. 1) is its low weight, i.e., it provides an unloaded state. For this reason, the values of some geometric parameters may show a higher value under load than the values recorded by the TrackScan 4.01 instrument.

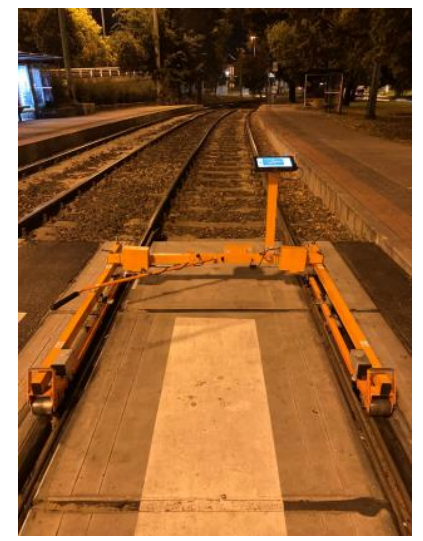

Figure 1

TrackScan 4.01 instrument (own made photo)

BKV PLC with Metalelektro Méréstechnika Ltd. commissioned the measuring tram in 2017 (Fig. 2). The vehicle dynamics measuring system has been installed on an eight-axle GANZ tram, which consists of the following fixed installation units [11]:

- Seven pieces of 3-axis accelerometer sensors

- GPS receiver and road sign receiver

- Two video cameras

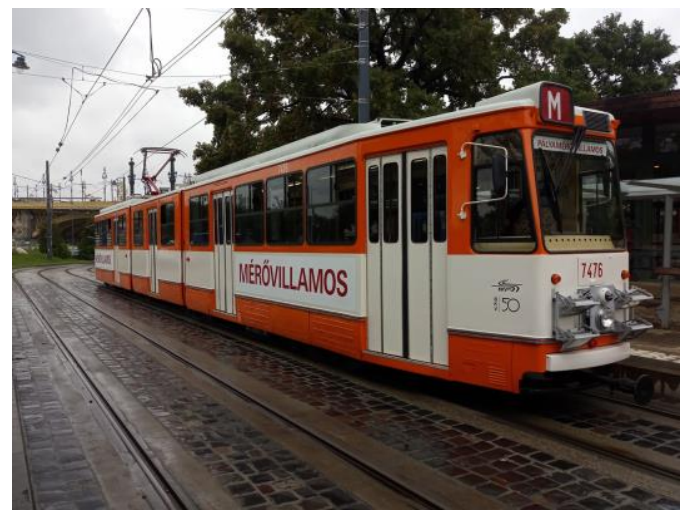

Figure 2

Measuring tram (own made photo) 
The sensors and cameras are connected to two systems that record the condition of the track and the catenary separately.

The data collector system of the vehicle dynamics measurement consists of the accelerometers (Fig. 3):

- Four sensors placed on wheels, which captures the tangent, radial, axial accelerations

- Two sensors placed on a longitudinal beam of boogie and one sensor placed on the car body captures accelerations perpendicular to the direction of measuring and accelerations in the direction of measuring [11].

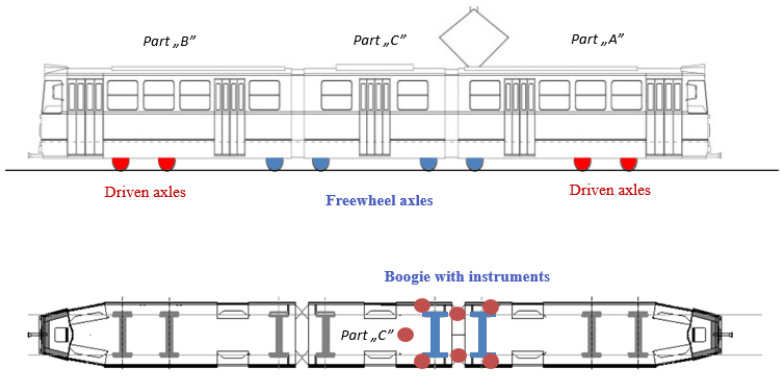

Figure 3

Placed sensors on measuring tram [11]

The accelerometers are located in the Part " $\mathrm{C}$ " of the tram, on the boogie closer to the Part "A".

The measuring system of tracks provides the following parameters for the rails (in parentheses are the units of each parameter, where unit ' $\mathrm{g}$ ' means gravitational acceleration):

- Vertical impact [-]

- Transversal impact [-]

- Vertical excess load [g]

- Transversal excess load $[\mathrm{g}]$

- Intensity of corrugation [-]

The parameters provided for the complete track are the following:

- Derailment safety characteristic $\left[\mathrm{g}^{3}\right]$

- Vertical travel comfort $[\mathrm{g}]$

- Transversal travel comfort $[\mathrm{g}]$ 
- Changing of lateral acceleration $[\mathrm{g}]$

- Vertical excess load of track characteristic [-]

There are cameras at the " $\mathrm{A}$ " and " $\mathrm{B}$ " ends of the tram, which takes continuous shots during the measurements. Budapest's entire tram(way) network is surveyed twice a year, usually in April and October. Measures are required at least six times at weekends because the ideal measurement speed is $25-30 \mathrm{~km} / \mathrm{h}$ [11].

\section{Methods}

In the research, the measurements have been performed on tramway line No. 1 in Budapest. The measurements are related to three years: in autumn of 2019 and 2020; and in spring of 2021. Vehicle dynamics measurements were executed almost simultaneously with the track geometry measurements. The nearly 18 kilometers long line is the second busiest line in the capital, four of the six superstructure systems here are examined [10]:

- Concrete slab track

- $\quad$ ESCRB I track system (ESCRB means elastically supported continuous rail bedding system)

- $\quad$ ESCRB III track system

- Ballasted track system

In this article, the measurement results of two sections will be presented, which are of different ages. The sections are ESCRB III track system, which is the most modern technology today (Fig. 4). The reinforced concrete overpass was embedded by homogenous continuous elastic support along the entire length of the rails. The paved superstructure system was built with 51R1 rail (i.e., grooved rail) profiles. The special feature of this, is that, there are no steel fastenings used. 


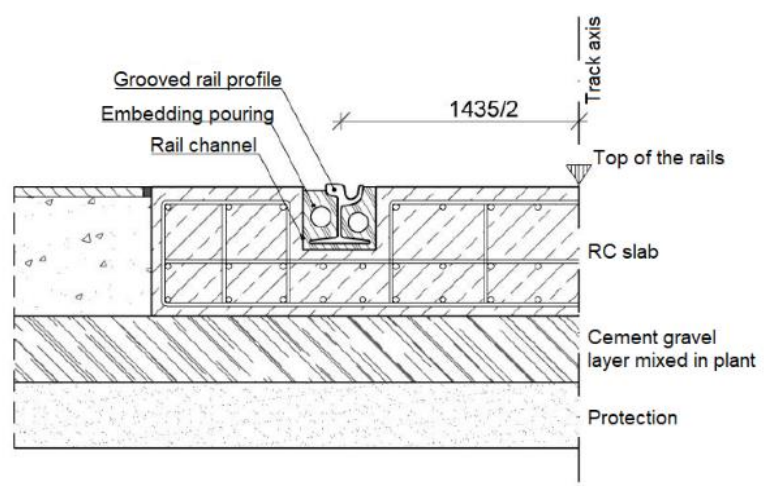

Figure 4

Cross-section of ESCRB III track system [9, 10]

Both presented sections are on bridges, the first one is the Árpád Bridge (superstructure was built in 2014), and the second one is the Kacsóh Pongrác overpass (superstructure was built in 2001). The tracks are straight, and there is no turnout or level crossing but several rail expansion devices; however, this article does not cover their examination.

In Budapest, each tramway line can be classified according to the traffic load; the classification depends on the annual through-rolled tonnages (Table 1).

Table 1

Traffic load classes [9]

\begin{tabular}{|c|c|c|}
\hline \multicolumn{2}{|c|}{ Traffic load class } & MGT/year/direction \\
\hline I/A & Extremely heavy loaded line & $>7.5$ \\
\hline I/B & Heavily loaded line & $5.0 \ldots 7.5$ \\
\hline II & Medium loaded line & $2.5 \ldots 5.0$ \\
\hline III & Low loaded line & $<2.5$ \\
\hline
\end{tabular}

The through-rolled axle tonnage is the mass of all crossing vehicles on a given line in one direction in one year. It is determined by multiplying the total number of crossing vehicles on the line and the average of the T0 loading (serviceable vehicle without crew and passenger) and T3 loading (serviceable vehicle with staff and maximum passenger capacity). In the case of the examined sections, the value of the traffic load is the same; however, it has changed in the last three years (Fig. 5). 


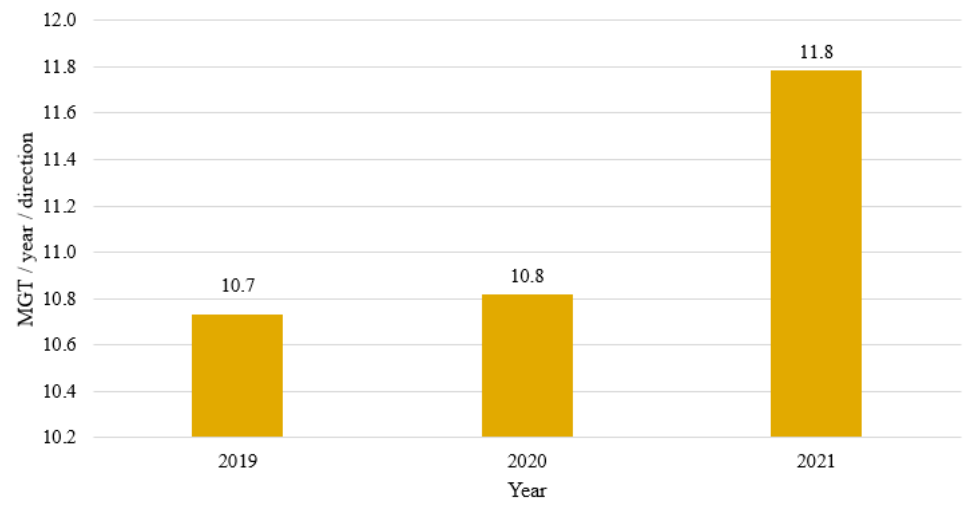

Figure 5

Traffic load of examined sections in the last three years

The figure shows that the investigated sections have extremely high loadings based on the load data. The data for 2019 and 2020 were determined on the basis of the actual completed runs, but for 2021 it is only an estimated value based on the actual completed runs in one week.

The following measured parameters of the Trackscan 4.01 instrument are considered:

- Track gauge [mm]

- Superelevation [mm]

- Alignment [mm]

- Longitudinal level [mm]

Among the dynamic characteristics measured and recorded by the measuring tram, those will be considered which can be related to track geometry parameters. These are as follows (unit ' $\mathrm{g}$ ' means gravity acceleration):

- Vertical impact [-]

- Transversal impact [-]

- Transversal excess load $[\mathrm{g}]$

- Changing of lateral acceleration $[\mathrm{g}]$

- Transversal travel comfort [g]

The relationships between each track geometry and vehicle dynamics parameters are shown in Table 2 [11]. In Table 2, the " $\mathrm{X}$ " symbols mean there is connection; where there is not anything in the brackets there is no assumed or certified connection. 
Table 2

Relationships between track geometry and vehicle dynamics characteristics

\begin{tabular}{|c|c|c|c|c|c|}
\hline \multicolumn{2}{|c|}{} & \multicolumn{3}{c|}{ Track geometry characteristics } \\
\cline { 3 - 6 } & $\begin{array}{c}\text { Track } \\
\text { gauge }\end{array}$ & $\begin{array}{c}\text { Super- } \\
\text { elevation }\end{array}$ & Alignment & $\begin{array}{c}\text { Longitudinal } \\
\text { level }\end{array}$ \\
\hline & Vertical impact & & & & $\mathrm{X}$ \\
\hline & Transversal impact & & & & $\mathrm{X}$ \\
\hline \\
\cline { 1 - 6 } \\
\hdashline
\end{tabular}

There is currently no measuring device installed on the measuring tram, to measure the values of the track geometry parameters. Therefore, the parameter is not directly or indirectly comparable to the measured dynamic characteristics. For this reason, the evaluation of the measurement results of the track geometry parameter is not reported in this article.

\section{Results and Discussion}

The track geometry and vehicle dynamic characteristics of the sections (see Chapter 3) are compared. Since the superelevation characteristic can only be related to one vehicle dynamic characteristic, its analysis was not fulfilled.

First of all, the possible correlations between the values of the longitudinal level track geometry parameter and the vertical and transversal impact parameters were examined for both sections. The measuring tram measures the impact values on both rails separately, the average of these was calculated during the evaluation.

Fig. 6 shows the average values of the measured and evaluated parameters. The change of average values of longitudinal level is shown as a second axis ' $y$ ' in the diagram. Based on the assumed relationship between vehicle dynamics and track geometry, the expected result is that the transversal and vertical impact values increase proportionately to the longitudinal level values. However, Fig. 6 contains the highest average of vehicle dynamic characteristics for both sections was in the third year, as the longitudinal level values decreased compared to the previous year's data. 


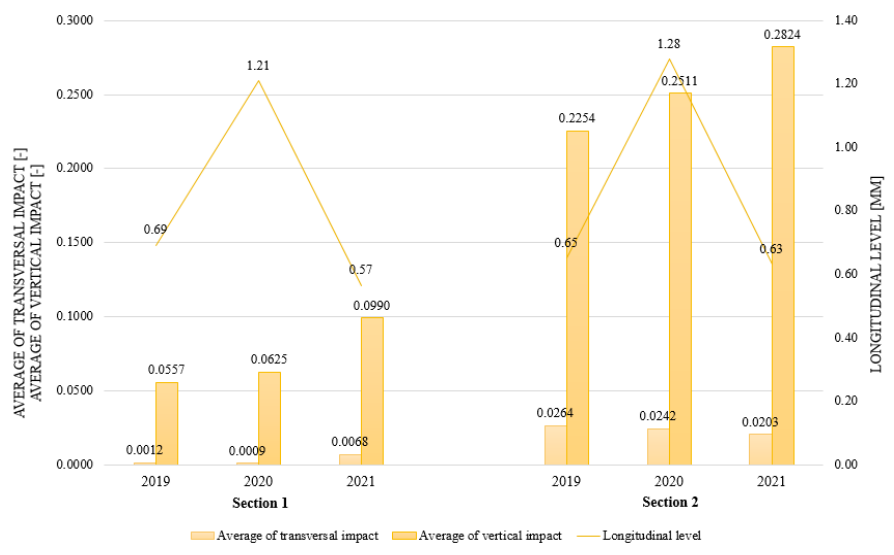

Figure 6

Comparison of the average of transversal \& vertical impact and longitudinal level

For this reason, in addition to the examined average values, it was necessary to look for points in the sections where the value of longitudinal level is high, and both vertical and transversal impact appear (Fig. 7). In general, the principal longitudinal level value appeared in the case of several cross-sections and the transversal and vertical impact values in the same or close cross-section (vertical lines in Fig. 7). But, of course, there are also cases when the examined characteristics cannot be related to each other. There may be several reasons for this, including the fact that it is difficult to reconcile the sectioning of the two instruments.

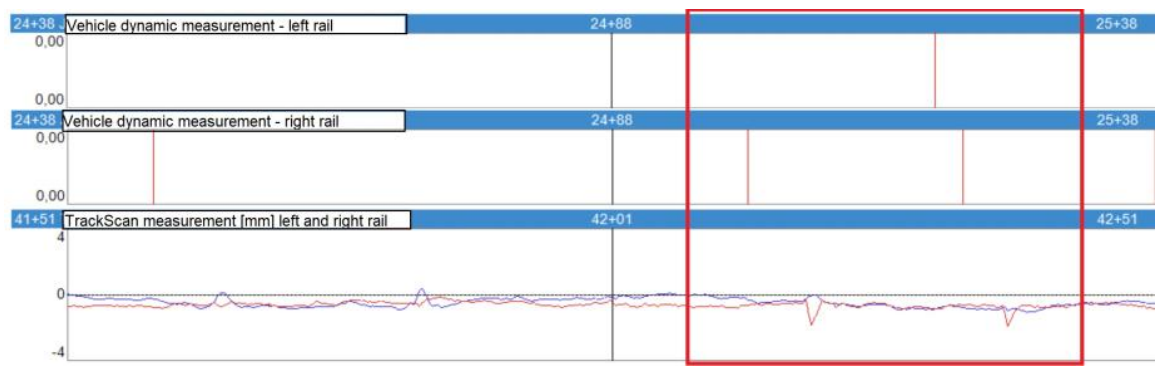

Figure 7

Comparison of transversal \& vertical impact vehicle dynamic values and longitudinal level track geometry value - Section 1,2021

Based on the hypothesized relationship between vehicle dynamics and track geometry, the alignment, and transversal excess load, changing of lateral acceleration, and transversal travel comfort's connection was also examined. Fig. 8 shows the average values of the measured and evaluated parameters and the change of average values of alignment. In this case, too, it was expected that there 
would be a clear proportional relationship between the alignment and the examined vehicle dynamic values. Nevertheless, the increase of the average value of the alignment parameter characteristic of the third year is not followed by the change in the average value of the dynamic characteristics.

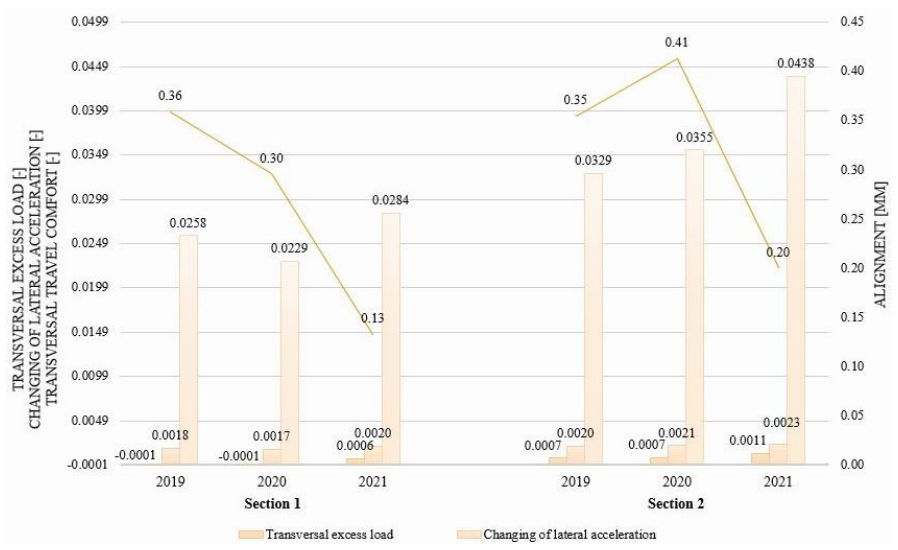

Figure 8

Comparison of average of transversal excess load, changing of lateral acceleration, transversal travel comfort and alignment

As in the previous case, it was necessary to find representative points from the measurement results where the values of geometric and dynamic characteristics are outstanding. Fig. 9 shows that the dynamic parameters theoretically related to the alignment parameter also appear in identical or nearly identical cross-sections. In this case, too, the values of the individual characteristics may not be compatible. The reasons for this have already been described above.

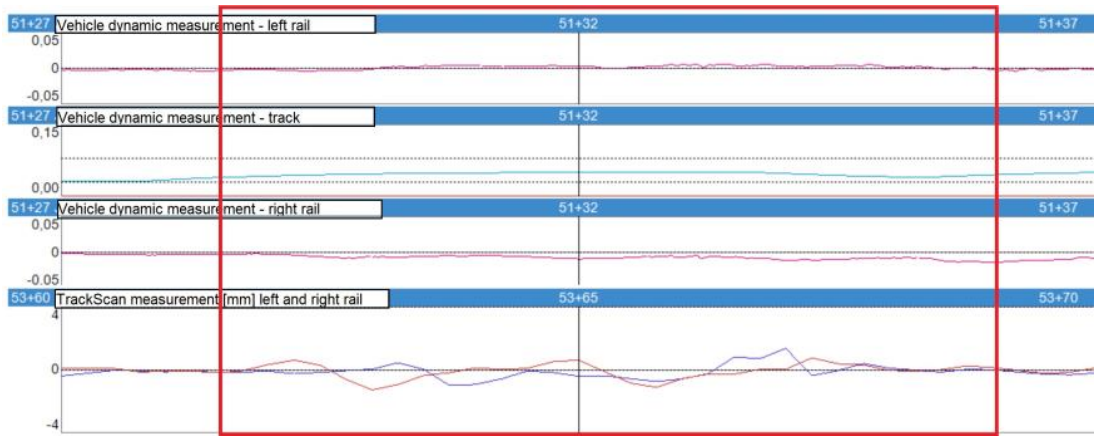

Figure 9

Comparison of transversal excess load, changing of lateral acceleration and transversal travel comfort vehicle dynamic values and alignment track geometry value - Section 2, 2021 


\section{Conclusions}

The deterioration of tramway tracks can be observed in several ways: the deterioration of the tracks' structural elements or changes in track geometric parameters. In addition to monitoring changes in geometrical characteristics, it is also essential to measure the dynamic characteristics of vehicles, record and assess the measurement results.

Suppose the geometric and dynamic measurements are appropriately evaluated, and the costs are known for the whole lifetime; the life cycle, geometric deterioration, and life cycle cost of each superstructure system can be determined.

In Hungary, the TrackScan 4.01 instrument and the measuring tram are applied for examination of the superstructure systems of tramway tracks at BKV PLC. In this article, the measurement results of two sections have been presented, which are of different ages. The sections are ESCRB III track system, which is the most modern technology today.

The relationships between each track geometry and vehicle dynamics parameters were considered. Based on the assumed relationship between vehicle dynamics and track geometry, the expected result is that the transversal and vertical impact values increase proportionately to the longitudinal level values. However, the highest average of vehicle dynamic characteristics for both sections was in the third year, as the longitudinal level values decreased compared to the previous year's data. For this reason, in addition to the examined average values, it was necessary to look for points in the sections where the value of longitudinal level is high, and both vertical and transversal impact appear.

The relationship between alignment and transversal excess load, changing of lateral acceleration, and transversal travel comfort was also examined. In this case, too, it was expected that there would be a clear proportional relationship between the alignment and the examined vehicle dynamic values. Nevertheless, the increase of the average value of the alignment parameter characteristic of the third year is not followed by the change in the average value of the dynamic characteristics. Therefore, as in the previous case, it was necessary to find representative points from the measurement results where the values of geometric and dynamic characteristics are outstanding.

Based on the presented results, it can be stated that the relationship between track geometry and vehicle dynamics characteristics needs further investigation. As the annual change in the average values of the parameters cannot yet be related to each other, cross-sections in which both geometric and dynamic values show outliers should be examined. It is also essential to find and formulate the relationship between the parameters with further measurements and tests, thus helping to determine the lifetime, the life-cycle, geometric deterioration, and lifecycle cost of each superstructure system. The methodology for this kind of assessment is in progress, because many values (measurements), are needed for it. It will be developed and improved in future work. 


\section{Acknowledgement}

This work was supported by BKV PLC.

\section{References}

[1] M. Ahac, S. Lakušić, Tram track maintenance-planning by gauge degradation modelling. Transport, Vol. 30, No. 4, 2015, pp. 430-436

[2] U. Gerber, M. Sysyn, J. Zarour, O. Nabochenko, Stiffness and strength of structural layers from cohesionless material. Archives of Transport, Vol. 49, No. 1, 2019, pp. 59-68

[3] D. Kurhan, M. Kurhan, Modeling the Dynamic Response of Railway Track. IOP Conference Series: Materials Science and Engineering, Vol. 708, No. 1, 2019, 012013

[4] R. M. Movahedi, S. K. Ibrahim, Optimal plastic analysis and design of pile foundations under reliable conditions. Periodica Polytechnica Civil Engineering, Vol. 65, No. 3, 2021, pp. 761-767

[5] M. Sysyn, O. Nabochenko, V. Kovalchuk, M. Przybyłowicz, S. Fischer, Investigation of interlocking effect of crushed stone ballast during dynamic loading. Reports in Mechanical Engineering, Vol. 2, No. 1, 2021, pp. 65-76

[6] D. Pamučar, D. Marinković, S. Kar, Dynamics under uncertainty: Modeling simulation and complexity. Mathematics, Vol. 9, No. 12, 2021, 1416

[7] A. J. Tigh Kuchak, D. Marinkovic, M. Zehn, Finite element model updating - Case study of a rail damper. Structural Engineering and Mechanics, Vol. 73, No. 1, 2020, pp. 27-35

[8] M. Kazemian, F. Astaraki, M. R. Movahedi, A. Taheri, Condition monitoring of vibration at weak parts of rail for ballasted railway tracks in Iran. Journal of the Korean Society for Railway, Vol. 24, No. 6, 2021, pp. 544-551

[9] BKV Zrt. Közúti vasúti infrastruktúra tervezési irányelvek (Guidelines of infrastructure planning of tramway tracks) 2019

[10] V. Jóvér, L. Gáspár, S. Fischer, Investigation of geometrical deterioration of tramway tracks. Nauka ta progres transportu, Vol. 86, No. 2, 2020, pp. 46-59

[11] Metalelektro Kft., A közúti vasúti vágányok pályaállapot-felmérésére alkalmas, Ganz 8 tengelyes villamos motorkocsira felszerelt, inerciális szenzor alapú képrögzíő rendszerrel kiegészített jármüdinamikai mérörendszer (Vehicle dynamics measurement system for the track condition of tramway tracks, equipped with a Ganz 8-axle EMU with an inertial sensor-based image recording system) 2016 